\title{
Editorial: The Future of Research in Gerontology: Problem, Issue, or Crisis?
}

Last year, the Social Sciences and Humanities Research Council of Canada (SSHRC) announced that it was abolishing Committee 20: Health Studies and Social Work of its research grants program and directed that applications deemed to be health research should be sent to the Canadian Institutes of Health Research (CIHR) grants programs. As a general policy, SSHRC also made it clear that those researchers applying to other programs (e.g., doctoral awards) when the proposal is health related should apply to CIHR. My understanding is that the National Science and Engineering Research Council (NSERC) made a similar policy decision. Obviously, those who already have funding are not affected. The other noticeable trend within all three councils is the increasing number of bilateral and trilateral calls for targeted funding research.

From a positive perspective, one might argue that these decisions have brought clarity to the roles of the funding councils and stopped "double" and "triple" dipping, whereby a small number of researchers are funded by two or even all three councils. By double and triple dipping, I do not mean to imply that researchers are submitting the same proposals to more than one funding council; this is obviously against the rules of the funding councils, and we should all be against this. What I mean is that some researchers receive funding for different but related proposals from more than one funding council or, by the very nature of having funding from more than one funding council, for completely separate projects. Consequently, some in the research community feel this is unfair because they believe no one should have the opportunity to apply to more than one council in the same year or to receive funding from more than one funding council at any one time. If you do not believe me, ask your colleagues why doctoral students are not allowed to apply to SSHRC and CIHR in the same year and then choose one even if they are awarded grants from both.

From my perspective, why should such double or triple dipping be a problem? In a field like gerontology research for which, by definition, incorporates the humanities, the social sciences, the natural sciences, and health - why should an individual researcher or group of researchers, whose proposals meet the criteria of excellence of any of the council panels, be penalized? Why should gerontology researchers, whose ideas span two or three areas of the funding councils, be compelled arbitrarily to choose where to send a grant proposal?
Is this really an issue of crafting proposals? Anecdotally, I am already hearing of researchers who, when they apply to SSHRC, frame their proposals about aging and well-being, the social determinants of aging or aging in the community. When they apply to CIHR, the terminology is aging and health, the social determinants of health or healthy aging. Before anyone starts sending me e-mails, I am not implying that there is anything unethical about doing this: that there is a one-to-one correspondence between terms, or that researchers who apply to SSHRC and use a particular term are indeed only interested in the social side of gerontology, and, similarly, those applying to CIHR are focused only on the health of the older population. My concern is whether the decisions made by the funding councils are forcing researchers to make these kinds of choices, especially those of us who see our research spanning some combination of health and the social sciences and humanities, or health and the natural sciences. Why should we be forced to decide whether there is "too much" health content in a proposal to send it to SSHRC, or "too much" social science or humanities content to send a proposal to CIHR?

Is this really a crisis of bureaucracy trumping intellect? Unfortunately, I think the answer is yes. The decision to divide health research from research in the social sciences and humanities and/or the natural sciences strikes at the essence of the multidisciplinary and interdisciplinary nature of gerontology. Although there are obviously research projects concerning the older population that focus purely on health, social science, humanities, or natural science, in much of what we do we need to consider health as an integral part of our social science, humanities, or natural science research, and vice versa. To do otherwise limits our thinking and also limits the contributions we can make to improving the lives of older Canadians.

I have the greatest respect for my colleagues at all three funding councils, and I think they work extremely hard trying to promote and, indeed, defend our interests with the limited resources available to them. I also appreciate that the pressure to define more clearly the boundaries of the funding councils and to do more targeted research is coming from higher levels of the government.

There will always be people who, because of their excellence, find success with more than one funding council, but the spirit of the changes as I see them is 
really to create a bureaucratic division among the three funding councils - except where the funding councils decide, in their bilateral or trilateral programs, what topics they think should be funded at a cross-disciplinary level. I see this as a very dangerous direction because it leads to politically driven agendas from higher up and is exclusionary by definition. The decisions that have been made are a problem, an issue, and indeed a crisis for gerontology in Canada. As gerontologists, we must speak out.

As always, please contact me at mark.rosenberg@ queensu.ca if you have any thoughts about this editorial or any other aspect of the $C J A / R C V$.

Mark W. Rosenberg

Editor-in-Chief 